\title{
The Impacts of Consumers' Familiarity on Their Behavioral Intentions towards Frozen Pangasius Products: A Study in Ho Chi Minh City, Vietnam
}

\author{
Phuong V. Nguyen ${ }^{1}$, Nhi H. X. Dang ${ }^{1}$, Quyen L. N. Do ${ }^{1} \&$ Kien T. Mai $^{1}$ \\ ${ }^{1}$ School of Business, International University-VNU-HCMC, Vietnam \\ Correspondence: Phuong V. Nguyen, School of Business, International University-VNU HCMC, Vietnam. Tel: \\ 84-8-3724-4270. E-mail: nvphuong@hcmiu.edu.vn
}

Received: January 22, 2015 Accepted: February 25, 2015 Online Published: May 14, 2015

doi:10.5539/res.v7n7p97 URL: http://dx.doi.org/10.5539/res.v7n7p97

\begin{abstract}
The paper aims to examine the impacts of product familiarity on the intention of customers in purchasing frozen pangasius products in Ho Chi Minh City, Vietnam. Quantitative surveys were conducted, in which 300 valid responses were used for data analysis. Based on previous studies in consumer behaviors, five hypotheses to test the effects of familiarity on behavioral intentions of purchasing pangasius products were proposed, which were implemented by structural equation modeling (SEM) technique. The data analysis showed that three independent factors (i.e. product knowledge, product involvement, and social-environmental impacts), except information approach, are positively correlated with product familiarity, which also plays an essential role in identifying the behavioral intention toward pangasius products. Furthermore, the empirical results also demonstrated that gender and age have no impact on consumers' behavior intentions. The results from this research could benefit for the aquaculture industry, especially business enterprises. Furthermore, this study provides a wide view to recognize the influences on behavior intentions towards frozen pangasius products in Ho Chi Minh City, Vietnam.
\end{abstract}

Keywords: pangasius products, behavioral intentions, product familiarity, knowledge, involvement

\section{Introduction}

\subsection{Introduce the Problem}

With the trend of urbanization, people have become busier earning for their living, especially those living in big cities. Therefore, their time for cooking is usually shortened than before and using frozen or canned products has become one of their most favorite choices since it can bring time utilization to consumers. When it comes to frozen aquaculture products, it can be seen that they have become more and more familiar to many households in dynamic cities and contribute to the diversity of the food products for Vietnamese consumers. The frozen-food market has developed from $20-40 \%$ each year, in which products from pangasius are among the most popular frozen ones favored by consumers. According to the Sales Department of Big C Supermarket, within the first two months of 2012, the consumption of pangasius products increased $20 \%$ compared to the same period last year. Furthermore, in recent years, the number of supermarkets and convenient stores in Ho Chi Minh City has been growing rapidly with the jump of both domestic and foreign investments. Up to December 31, 2011, there were about 140 supermarkets and more than 500 convenient stores in Ho Chi Minh City. They have become one of the fastest and most convenient channels operated to bring products closer to consumers; therefore, they can be the appropriate places for food-processing firms to introduce their products to domestic consumers. In addition, with the population of more than 86 million people, the Vietnamese domestic market becomes a very promising segment for food-processing firms in general and aquaculture products processing firms in particular.

\subsection{Explore Importance of the Problem}

As mentioned above, Ho Chi Minh City is one of the largest and most dynamic cities in Vietnam. The bustle at work every day makes people now prefer something fast and convenient but still healthy and nutritious for an affordable price; thus, frozen food has become popular in many supermarkets in the city recently. Although researchers have determined the predominant driving factors of customer behavior intention in many commodities such as mobile services (Guo \& Barnes, 2011; Shin \& Shin, 2011), or vegetable products (Kamphuis et al., 2006; Kamphuis et al., 2007; Sabbe, Verbeke, \& Van Damme, 2008), there are a few studies 
about a specific kind of food products like pangasius. Therefore, this study aims to analyze what factors influence on the familiar feelings among consumers in Ho Chi Minh City towards frozen pangasius products and how the level of familiarity could affect their behavioral intentions. Important factors, which could dominate in predicting consumers' behavior such as product knowledge, product involvement, were also incorporated. Then, several previous studies will be reviewed in order to build up the research model with some hypotheses. Based on the results, aquaculture food-processing firms can enable to improve their business strategies to enhance customers' feeling of familiarity towards those products and attract their intention of purchasing. Besides, this study can also help firms that pay more attention to increasing the market shares. The next section presents the research methodology and then explain research results, which are analyzed by structural equation modeling. Finally, the final section discusses the main results together with implications and conclusions.

\section{Literature Review}

\subsection{Consumer Familiarity}

According to Sirgy (1981), product familiarity has become a fresh variable in the study of consumer behavior. Marks and Olson (1981) defined "product familiarity is conceptualized in terms of the cognitive structures of knowledge concerning the product stored in memory. Such knowledge could have been derived from direct or indirect experiences." There are two suggested major approaches for organizing and measuring product familiarity. One was measured by understanding "how much a person knows about the product" and the other is "how much a person thinks he/she knows about the product" (Park, 1981). These two approaches could be used separately or associatively. Besides, some other studies also used product familiarity to explain many consumer-related phenomena such as message acceptance (Marks \& Olson, 1981), choice of decision rule (Parks, 1976; Tan \& Dolich, 1981), product preference and purchase intention (Marks \& Olson, 1981), product satisfaction and new learning (Johnson \& Russo 1984). However, there are some conflicts in using product familiarity as an explanatory variable. Due to the ambiguity shown in the conceptualization and measurement of product familiarity, it might cause the lack of clarity of the precise role of product familiarity as a determinant of consumer behavior (Sirgy, 1981).

Besides, according to Sujan and Bettman (1989), product and brand categories are graphically represented in consumer memory. Many consumer behavior studies have shown that the higher the familiarity of a specific product is, the more outstandingly the memory presentation about that product would be differentiated (Johnson \& Russo, 1984; Coupey et al., 1998). Another study has also determined the crucial role of product familiarity - a consumer's previous experience with the future product feature - in affecting new-product learning and evaluation (Alba \& Hutchinson, 1987).

Obviously, the concept of product familiarity is considered as an essential explanatory variable in many previous studies (Johnson \& Russo, 1984; Punj \& Staelin, 1983; Bettman \& Park, 1980). However, the problem here is that few studies have pointed out exactly what constructs constitute familiarity. The terms of product use, knowledge structure, and involvement have all been explored in line with the term familiarity (Zaichkowsky, 1985).

\subsection{Consumer Behavior and Behavior Intention}

Consumer behavior is defined as "the study of individuals, groups, or organizations and the processes they use to select, secure, and dispose of products, services, experiences, or ideas to satisfy needs and the impacts that these processes have on the consumer and society" (Kuester, 2012). According to Armstrong et al. (2000), customer behavior research is mostly based on consumer purchasing behavior, where the customers are playing the three different roles of user, payer, and buyer.

Behavioral intention is one type of consumer behavior in purchasing one typical product. It is defined as a person's perceived likelihood or "subjective probability that he or she will engage in a given behavior" (Committee on Communication for Behavior Change in the 21st Century, 2002, p. 31). Moreover, Ajzen (1991) argued that behavioral intention reflects how hard a person is willing to try and how motivated him or her to perform his or her behavior. In addition, Perner (2008) argued that behavior would occur either in individuals or the context of a group that influences such things like what kinds of clothes a person wears or what a person should behave in an organization. For another example, aggressive marketing of high-fat food or easy credit may lead to have serious consequences to the national health and the economy, respectively.

\subsection{Hypothesis Development}

\subsubsection{The Relationship between Product Knowledge and Product Familiarity}

The knowledge might come from actual product purchase or use in the past or from secondary sources. Past 
experiences of typical products could possibly affect the familiarity feelings of customers. The spread of related news or information could also positively impact the familiarity among consumers. It is commonly assumed that there is a strong relationship between product familiarity and consumer knowledge (Bettman \& Park, 1980; Johnson \& Russo, 1984). Therefore, the hypothesis was developed as follows:

H1: Consumer's product knowledge has a positive effect on product familiarity.

\subsubsection{The Relationship between Information Approach and Product Familiarity}

Familiarity has been the central of empirical work in consumer research, which are related to information acquisition (Bettman \& Park, 1980) or reaction to advertising (Marks \& Olson, 1981). This could be analyzed by understanding the way people use to approach the information about the products or by which ways the product information could be delivered to its customers. Thus, the following hypothesis was conducted:

H2: Information approaching has a positive impact on product familiarity.

\subsubsection{The Correlation between Product Involvement and Product Familiarity}

For product involvement, McQuarrie and Munson (1987) develop five criterion measures adapted from Zaichkowsky (1985) and Laurent and Kapferer (1985) in order to gain deeper insights of involvement consequences. In addition, the relationship between familiarity and product involvement was tested by the study about the impact of familiarity on decision confidence, decision time, satisfaction, and use of other attributes (Park \& Lessig, 1981). They found the noteworthy differences among low, medium, and high product familiarity subjects on the use of these decision heuristics and concluded that the subjects' level of involvement with the product category could have contributed to the results. The level involvement could vary between personal involvement and outside effects, which are from relatives, friends, or social media. In order words, product involvement is said to have an influence on product familiarity, as represented in the hypothesis below:

H3: Product involvement would have a positive impact on product familiarity.

\subsubsection{The Relationship between Social-Environmental Impacts and Product Familiarity}

Social-environmental impacts include human-related factors (i.e. other customers' behaviors) and environment-related factors (i.e. marketplace condition) (Kamphuis et al., 2006). Several studies have pointed out a positive impact of socio-environmental factors such as social supports from family and other persons on food intake (Kamphuis et al., 2006; Kamphuis et al., 2007; Wardle et al., 2004). In addition, the behavior of customers might affect the perception of a typical customer. In addition, the conditions at marketplaces could also impact on customers' frequency of visiting product counters. If the customers are attracted by those good conditions, they will feel familiar with the product even though they do not purchase it (Kamphuis et al., 2006; Kamphuis et al., 2007). Thus, a hypothesis is presented:

H4: Social-environmental factors could have a positive impact on product familiarity.

\subsubsection{The Relationship between Product Familiarity and Behavioral Intention}

According to McCarthy and Perreault (1984), one of the main objectives of a typical company is trying to satisfy its customers. Therefore, all activities will focus on the company's current customers and on attracting new ones. In order to develop its customer base, a company will also pay particular attention to consumers at large - its potential customers. In particular, it will look at consumers' wants, needs, and purchase intentions; all of which then will become valuable information for the company. As Armstrong et al. (2000) argued, purchase intentions are likely to provide better forecasts of future sales than a simple extrapolation.

Product familiarity could be used as a determinant of consumer behavior. According to Marks and Olson (1981) and Sabbe et al. (2008), the effect of product familiarity was related to message acceptance, product preference, and purchase intention. Product familiarity is also considered as an important role in the selection of decision rules (Tan \& Dolich, 1981). In addition, Marks and Olson (1981) also stated that the more the subjects felt familiar with the product, the more likely they will recommend their purchase to other people. Basing on the previous literature, we conduct a hypothesis as follows:

H5: Product familiarity would have a positive impact on customer behavioral intention of purchasing.

\subsection{Research Model}

Based on those research variables as well as the hypotheses above, the following research model as well as hypotheses are conducted as presented in Figure 1. Furthermore, some demographic factors were also included to control demographic characteristics of correspondents. 


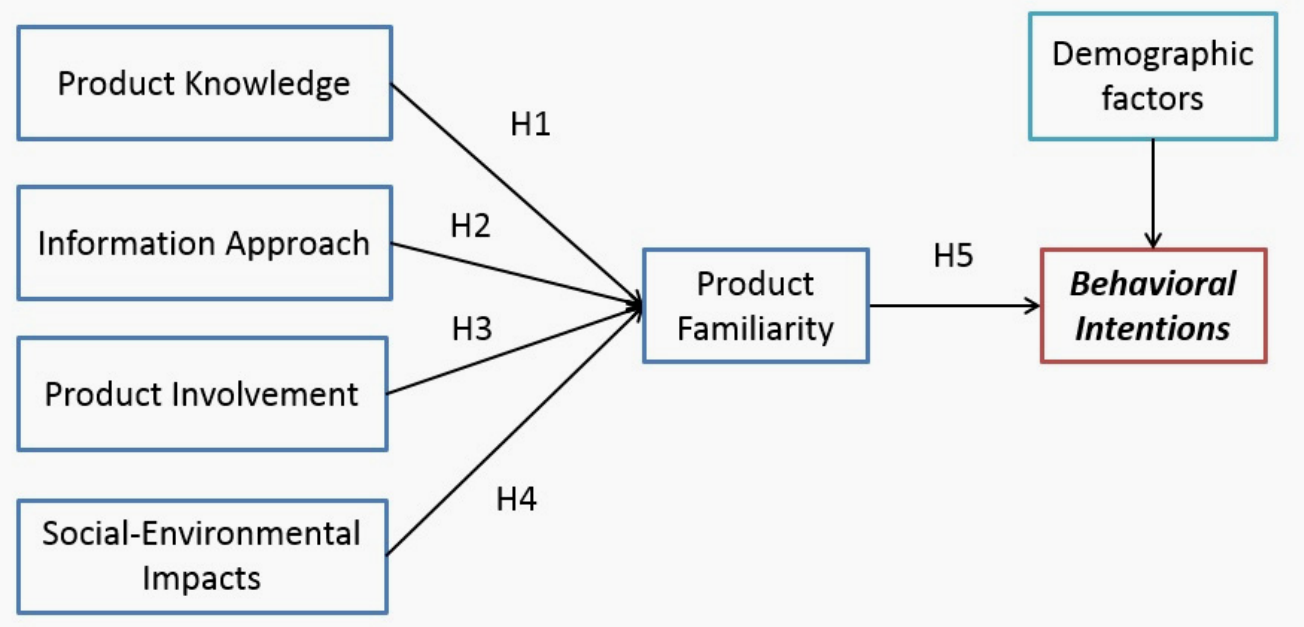

Figure 1. The research model

\section{Methodology}

\subsection{Data Collection}

In order to test our hypotheses, a survey questionnaire was developed and distributed in Ho Chi Minh City. We asked respondents who had known pangasius products and experienced in the last 12 months. A survey instrument was designed to ask interviewees if and how their behavioral intentions were affected by product familiarity, product knowledge, information approach, product involvement, and social-environmental factors.

The questionnaires include 29 questions about the product familiarity and behavioral intention towards frozen pangasius products among consumers in Ho Chi Minh City. We used 5-point Likert Scale from (1) Strongly Disagree to (5) Strongly Agree on the questionnaires to evaluate the items. The questionnaire also includes the demographic questions (age, income, career, gender and the frequency of product use. In preparing this study, we conducted a pilot test with 80 respondents to detect the weaknesses of our questionnaire in both Vietnamese translation and structure. Then, feedback from target respondents was collected so that the improvement of the questionnaires can be done. Data were collected by conducting both web-based and paper-based surveys with confident sampling methods, in which respondents were asked for filling in the survey. The survey was conducted in October of 2013. A total of 334 samples were received. After eliminating duplicate responses as well as those with low standard deviation in Likert Scale points (i.e. below 0.3), a total of 300 valid responses were included in the sample for analysis.

\subsection{Variable Measurement}

The independent variables are adapted from Johnson and Russo (1984), Bettman and Park (1980), McQuarrie and Munson (1987), Zaichkowsky (1985), and Kamphuis et al. (2006). Meanwhile, the indicators of the two dependent variables are adapted from Johnson and Russo (1984), Marks and Olson (1981), and Sabbe et al. (2008). The survey questions in details are illustrated in Table 1.

\subsection{Data Analysis Instrument}

In addition, we use two software including IBM SPSS Statistics 21 and SPSS AMOS 21 to analyze the dataset. Firstly, Exploratory Factor Analysis (EFA) is used to test the reliability of each factor and determine should the research model has any new extracted factors. Next, we use Confirmatory Factor Analysis (CFA) to evaluate the model fit from the factor structure extracted in EFA. Finally, to test the causal relationship, we explore Structural Equation Modeling (SEM), which implements the purposes similar to multiple regressions but in a more powerful method (Hair et al., 2010). 
Table 1. Constructs and item measurements

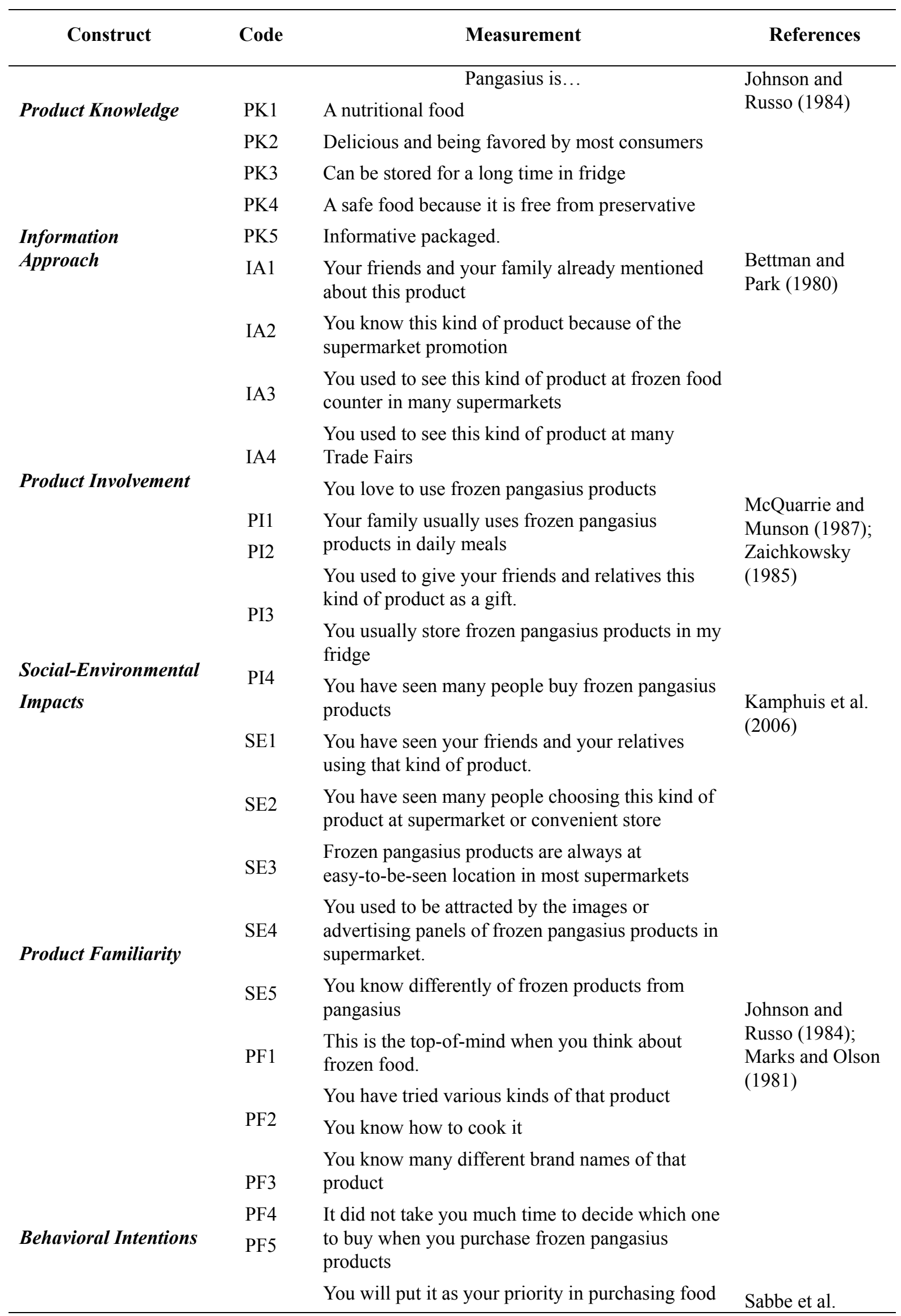


PF6 You will stay loyal to frozen pangasius products (2008) even when there is something better.

BI1 In the future, you will only buy frozen pangasius

BI2 products from familiar brand names

BI3

BI4 You will only buy what others recommend.

BI5 You will introduce this kind of product to others

\section{Data Analysis and Results}

4.1 Sample Demographic

Table 2. Sample demographic

\begin{tabular}{llcc}
\hline \multicolumn{1}{c}{ Factors } & \multicolumn{1}{c}{ Items } & Frequency & $\begin{array}{c}\text { Percentage } \\
(\mathbf{\%})\end{array}$ \\
\hline Gender & Male & 95 & 31.7 \\
& Female & 205 & 68.3 \\
Age & 18-25 years old & 207 & 69 \\
& 26-35 years old & 48 & 16 \\
Income & Over 35 years old & 45 & 15 \\
& Under 5 million VND per month & 179 & 59.7 \\
& 5-10 million VND per month & 67 & 22.3 \\
Occupation & 11-20 million VND per month & 34 & 11.3 \\
& More than 20 million VND per & 20 & 6.7 \\
& month & 169 & 56.3 \\
& Student & 115 & 38.3 \\
& Officer & 16 & 5.3 \\
\hline
\end{tabular}

Among 300 responses collected, there are $68.3 \%$ females and $31.7 \%$ male from different age ranges, occupation, and financial condition. Therefore, these responses could partly reflect the differences in perception, feelings, and psychology of respondents. The correspondents of ages 18-25 (69\%) accounted for the biggest proportion of the sample. Additionally, nearly $60 \%$ of the respondents' income were under 5 million VND per month, followed by the range from 5 to 10 million VND per month. With occupation, it can be observed from the table above that over a half of survey participants were students (e.g. high school, university, college students).

4.2 Main Survey Results

4.2.1 Reliability Test and Factor Analysis

Firstly, Cronbach's alpha is used to test whether each item of each factor is reliable or not. In order to have a reliable data, Cronbach's alpha should be above 0.7 ; however, values above 0.8 are preferable (Hair et al., 2010; Pallant, 2011). Furthermore, the Corrected Item-Total Correlation values shown in the Item-Total Statistics should be greater than 0.3 (Pallant, 2011). Therefore, all the items used in this study are reliable and preferable (see Table 3). 
Table 3 . Results of the reliability test

\begin{tabular}{llccc}
\hline \multicolumn{1}{c}{ Construct } & \multicolumn{1}{c}{ Measurement Item } & $\begin{array}{c}\text { Cronbach's } \\
\boldsymbol{\alpha}\end{array}$ & $\begin{array}{c}\text { Correlated } \\
\text { Value Range }\end{array}$ & $\begin{array}{c}\text { Number } \\
\text { of Items }\end{array}$ \\
\hline Product Knowledge & PK1, PK2, PK3, PK4, PK5 & 0.735 & $0.409-0.563$ & $5(5)$ \\
Information Approach & IA1, IA2, IA3, IA4 & 0.882 & $0.655-0.791$ & $4(4)$ \\
Product Involvement & PI1, PI2, PI3, PI4 & 0.805 & $0.588-0.630$ & $4(4)$ \\
Social-Environmental impacts & SE1, SE2, SE3, SE4, SE5 & 0.818 & $0.593-0.753$ & $5(5)$ \\
Product Familiarity & PF1, PF2, PF3, PF4, PF5, PF6 & 0.868 & $0.631-0.703$ & $6(6)$ \\
& BI1, BI2, BI3, BI4, BI5 & & & \\
Behavioral Intention & & 0.843 & $0.612-0.689$ & $5(5)$ \\
\hline
\end{tabular}

Note. Initial Items (Final Items).

Secondly, we come to EFA test. According to Hair et al. (2010), KMO value must be above 0.5 and significant result must be below 0.05. In addition, factor loadings of each item in Pattern Matrix are preferable if it is greater than 0.5 . In our case, the KMO value $(0.779)$ and significant results $(p<0.001)$ are appropriated after eliminating some invalid items. As a result, the KMO value changed to 0.777 , with all indicators exceed the threshold of 0.5 in outer loading. The final results of EFA analysis are reported as follows:

Table 4. Exploratory factor analysis results

\begin{tabular}{|c|c|c|c|c|c|c|}
\hline \multirow{2}{*}{ Item } & \multicolumn{6}{|c|}{ Factor } \\
\hline & PF & BI & IA & SE & PI & PK \\
\hline PF5 & .781 & & & & & \\
\hline PF3 & .748 & & & & & \\
\hline PF2 & .748 & & & & & \\
\hline PF4 & .710 & & & & & \\
\hline PF6 & .708 & & & & & \\
\hline PF1 & .663 & & & & & \\
\hline BI4 & & .755 & & & & \\
\hline BI2 & & .751 & & & & \\
\hline BI3 & & .736 & & & & \\
\hline BI1 & & .702 & & & & \\
\hline BI5 & & .656 & & & & \\
\hline IA2 & & & .868 & & & \\
\hline IA1 & & & .842 & & & \\
\hline IA3 & & & .827 & & & \\
\hline IA4 & & & .703 & & & \\
\hline SE2 & & & & .873 & & \\
\hline SE1 & & & & .741 & & \\
\hline SE3 & & & & .709 & & \\
\hline SE4 & & & & .644 & & \\
\hline PI1 & & & & & .744 & \\
\hline PI2 & & & & & .730 & \\
\hline PI4 & & & & & .717 & \\
\hline
\end{tabular}


PI3

.667

PK1

PK2

PK4

PK3

Note. Extraction Method: Principal Axis Factoring.

Rotation Method: Promax with Kaiser Normalization. ${ }^{\text {a }}$

${ }^{\text {a }}$ Rotation converged in 5 iterations.

\subsubsection{Confirmatory Factor Analysis (CFA)}

An initial analysis identified inadequate fit indices with coefficients among some variables. To adjust the model, we add covariance between some errors and remove those variables. The table below shows the initial and final fit index of the model.

Table 4. Initial and final index off it of the model

\begin{tabular}{|c|c|c|c|c|}
\hline \multirow{2}{*}{ Index } & \multicolumn{2}{|c|}{ Final analysis } & \multirow{2}{*}{ Criteria } & \multirow{2}{*}{ References } \\
\hline & Initial & Final & & \\
\hline Chi-squared/Degrees of freedom & 1.708 & 1.262 & $\leq 2-5$ & \multirow{6}{*}{$\begin{array}{c}\text { Hair et al. (2010); } \\
\text { Byrne (2010); } \\
\text { Tabachnik \& } \\
\text { Fidell (2001) }\end{array}$} \\
\hline p-value & 0.000 & 0.000 & $\leq 0.05$ & \\
\hline GFI-Goodness-of-fit & 0.881 & 0.916 & $\geq 0.9$ & \\
\hline AGFI-Adjusted Goodness of Fit Index & 0.856 & 0.896 & $\geq 0.8$ & \\
\hline CFI-Comparative Fit Index & 0.928 & 0.976 & $\geq 0.9$ & \\
\hline $\begin{array}{l}\text { RMSEA-Root Mean Squared Error of } \\
\text { Approximation }\end{array}$ & 0.049 & 0.03 & $\leq 0.08$ & \\
\hline
\end{tabular}

Table 4 demonstrates the removal of non-significant relationships and the insertion of covariance led to a substantial improvement in the values of adjustment when compared to the original model proposed. This table shows the fit indices values which satisfied the minimum requirements recommended by Hair et al. (2010). Therefore, we can conclude that constructs used in this research satisfy the reliability and validity criteria.

4.2.3 Results of the structural model (SEM)

Table 5. Estimates of structural path coefficients

\begin{tabular}{lccc}
\hline \multicolumn{1}{c}{ Path } & P-value & $\begin{array}{c}\text { Path } \\
\text { Estimate }\end{array}$ & Result \\
\hline Product Knowledge $\rightarrow$ Product Familiarity & $* *$ & 0.144 & Supported \\
Information Approach $\rightarrow$ Product Familiarity & 0.177 & -0.086 & Not Supported \\
Product Involvement $\rightarrow$ Product Familiarity & $*$ & 0.122 & Supported \\
Social-Environmental Impacts $\rightarrow$ Product Familiarity & $*$ & 0.115 & Supported \\
Product Familiarity $\rightarrow$ Behavioral Intention & $* * *$ & 0.287 & Supported \\
Age $\rightarrow$ Behavior Intention & 0.148 & -0.088 & Not Supported \\
Gender $\rightarrow$ Behavior Intention & 0.477 & -0.046 & Not Supported \\
\hline
\end{tabular}

Note. $*$ denotes $\mathrm{p}<0.1, * *$ denotes $\mathrm{p}<0.05$, and $* * *$ denotes $\mathrm{p}<0.01$. 
As can be seen from Table 8, Hypothesis 1, which proposed that product knowledge would have positive impacts on product familiarity, is confirmed. Hypothesis 2, which proposed that information approach would have positive impacts on product familiarity, is not confirmed because its p-value is above 0.1 at $90 \%$ of confident interval; therefore, a rejection of this hypothesis was conducted. In contrast, hypothesis 3 confirmed a positive impact of product involvement on product familiarity. Similarly, hypothesis 4 showed a significant relationship between social-environmental impacts and product familiarity. Besides, hypothesis 5, which proposed product familiarity would positively affect behavioral intention, was supported. Finally, demographic factors (i.e. age and gender) had no influence on the behavior intention, illustrated by their high p-values.

Besides, among the three factors, product knowledge, product involvement, and social-environmental factors, it can be seen that product knowledge has the strongest influence on product familiarity of customers with a path estimate value of 0.127 ; however, this value does not dominate the other impact power values. Furthermore, it should be noticed that product familiarity plays an important role in predicting consumers' behavior intention to buy pangasius products thanks to its high path estimate value $(0.279)$. The final model in this study is showed in figure 2 .

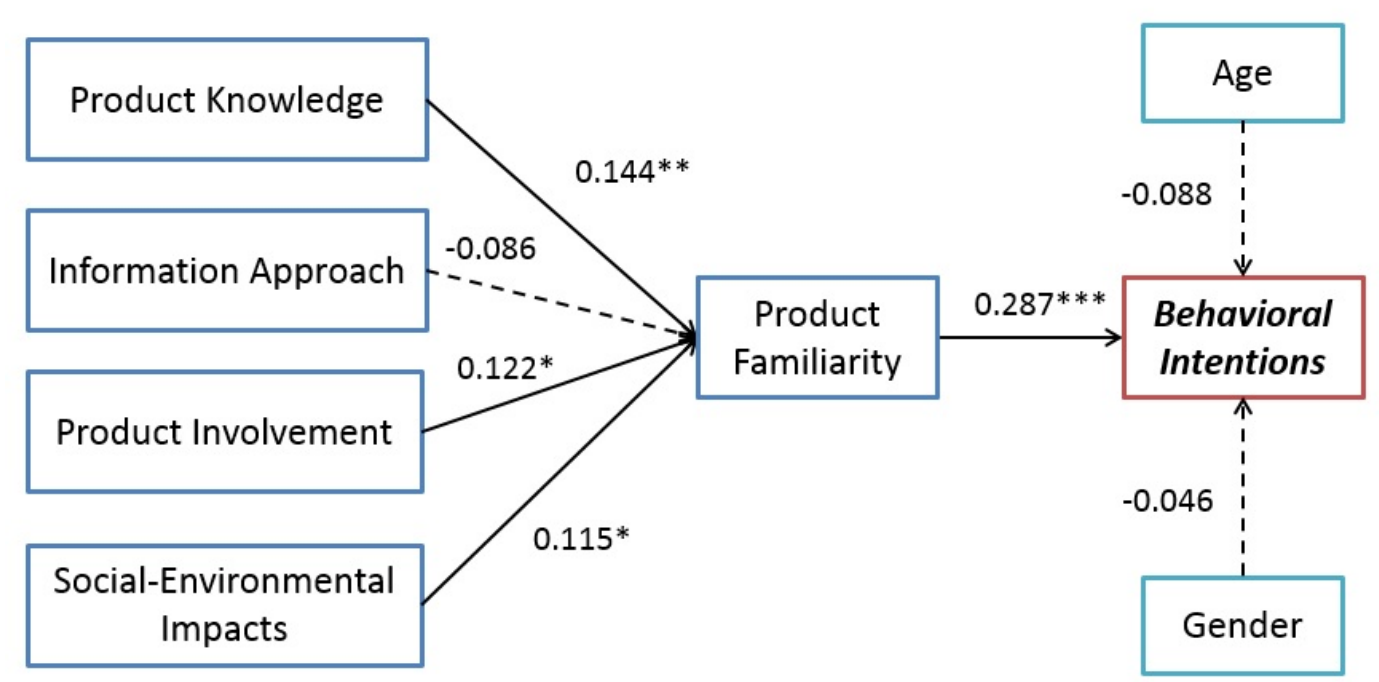

Figure 2. Final research model $\left({ }^{*} \mathrm{p}<0.1, * * \mathrm{p}<0.05\right.$, and $\left.* * * \mathrm{p}<0.01\right)$

\section{Discussion}

This study investigated the impact of product knowledge, information approach, product involvement, and social-environmental factors on product familiarity and consumers' purchase intention towards frozen pangasius products in Ho Chi Minh City. All the independent others than information approach were found to positively affect product familiarity, which in turn, has a significant impact on behavioral intention.

Firstly, this research found that product knowledge was positively associated with product familiarity towards frozen pangasius products. This finding is consistent with the initial hypothesis, meaning that the more people know about that product, the more likely they would use it. When consumers had usage experiences, they would be classified as high familiarity with that product (Park \& Lessig, 1981).

Secondly, the way product information gets to consumers has no impact on their familiarity towards that product. This finding is inconsistent with our hypothesis. However, this situation could be explained in the context of Vietnamese market. Obviously, frozen foods have become more popular in Vietnam; however, there is almost no advertisement for frozen pangasius products on TV and some popular newspapers. Therefore, it would be difficult for consumers to approach information about those products.

In addition, the study results showed that product involvement has significant impacts on product familiarity. Product involvement shows how confident the consumers are when buying/using specific products and what level they could be affected by the others when making decision. Therefore, if they feel familiar with frozen 
pangasius products, they will spend less time in purchasing/using the product and feel easy to choose an appropriated product type.

On the other hand, social-environmental factors also have positive effects on product familiarity. This finding is consistent with our initial prediction. This could be explained that consumers would feel more familiar with a typical product if they were provided information from other people (e.g. friends, relatives). Besides, consumers may also be attracted by one typical product in their usual shopping places through nice arrangement, large quantity, beautiful packages, or seeing many other people also buy that product. Once these positive feeling increases, the familiarity feeling also increases. Specifically, we find there is no difference in gender and age in purchasing intentions.

Finally, product familiarity plays an important role in predicting behavioral intention among customers as well. Consumers will be more confident in purchasing frozen pangasius products if they feel familiar with that product. Once they know a specific kind of product, its attributes, whether or not it is good for their health, or usage direction, they will feel safe when using it. Once the familiarity of consumer increases, the probability they would purchase it will increase as well.

\section{Conclusion and Implications}

\subsection{Conclusion}

This study is conducted to see what factors affecting product familiarity among consumers in Ho Chi Minh City, Vietnam towards frozen pangasius products and how the product familiarity can influence their behavioral intentions. Four independent factors were used to test their impact on product familiarity (i.e. product knowledge, information approach, product involvement, and social-environmental impacts). The statistics from 300 respondents showed a significant influence of familiarity feelings on the behavioral intention to purchase pangasius products. Based on this study result, producers in frozen pangasius industry can build their marketing and branding strategies to promote their products and gain more market shares.

\subsection{Practical Implications}

This study proved that consumers' familiar feelings about frozen pangasius products depend on their knowledge about those products. Thus, pangasius processing companies can conduct some strategies to enhance consumers' perception about their commodities. For example, food-processing firms should widely provide positive attributes of products such as healthiness, good taste, and safety through their marketing campaign. In addition, those firms should also create more chances for consumers to try their products because the more consumers believe in their experience, the more likely their familiarity towards frozen pangasius products will increase.

Furthermore, product involvement is considered as a crucial role in increasing product familiarity of consumers toward frozen pangasius products. Therefore, it is important that food-processing enterprises should clearly identify the focus of consumers' involvement. They need to know exactly what consumers consider to be personally relevant: a product or brand, a behavior, an event, a situation, an environment, or several of these together (Peter and Olson, 2011). Increasing the intrinsic self-relevance and improving consumer's situational self-relevance are also some essential ways to enhance the involvement of consumers and products.

This study also proved that social and environmental factors do have positive impacts on consumer familiarity towards frozen pangasius products. Therefore, creating the social trends and improving a shopping environment for frozen pangasius products are what the processing firms need to consider in order to capture the largest market shares. An appropriate way to conduct promoting frozen pangasius products is to focus on young consumers (university students and young officers) whom easily to be affected by social trends. Therefore, food companies should pay attention in creating advertisements with interesting and meaningful messages for teenagers or students. Besides, those companies can also offer some special product lines for a typical segmentation, which can provide enough energy and nourishing for university students. Last but not least, it is necessary for pangasius products to be tidily arranged in shopping places like supermarkets in order to catch consumers' attention more easily.

\section{Research Limitations and Recommendation for Further Studies}

This study has investigated only the determinants of product familiarity to find out their influences on the behavioral intention of pangasius products. Future research can add in the research model and includes some other determinants like social norms, perceived usefulness, and so forth. In addition, this study could also be conducted in some other big cities in Vietnam such as Hanoi, Danang, Cantho. The research could expand the area of study to gather more insights about the larger pangasius market. 


\section{References}

Ajzen, I. (1991). The theory of planned behavior. Organizational behavior and human decision processes, 50(2), 179-211. http://dx.doi.org/10.1016/0749-5978(91)90020-T

Alba, J. W., \& Hutchinson, J. W. (1987). Dimensions of consumer expertise. Journal of consumer research, 411-454. http://dx.doi.org/10.1086/209080

Armstrong, J. S., Morwitz, V. G., \& Kumar, V. (2000). Sales forecasts for existing consumer products and services: Do purchase intentions contribute to accuracy? International Journal of Forecasting, 16(3), 383-397. http://dx.doi.org/10.1016/S0169-2070(00)00058-3

Bettman, J. R., \& Park, C. W. (1980). Effects of prior knowledge and experience and phase of the choice process on consumer decision processes: A protocol analysis. Journal of Consumer Research, 234-248. http://dx.doi.org/10.1086/208812

Byrne, B. M. (2010). Structural equation modeling with AMOS: Basic concepts, applications, and programming. http://dx.doi.org/10.1086/209031

Coupey, E., Irwin, J. R., \& Payne, J. W. (1998). Product category familiarity and preference construction. Journal of Consumer Research, 24(4), 459-468. http://dx.doi.org/10.1086/209521

Guo, Y., \& Barnes, S. (2011). Purchase behavior in virtual worlds: An empirical investigation in Second Life. Information \& Management, 48(7), 303-312. http://dx.doi.org/10.1016/j.im.2011.07.004

Hair, J. F., Black, W. C., Babin, B. J., \& Anderson, R. E. (2010). Multivariate data analysis (7th ed., p. 654). Upper Saddle River, NJ, USA: Prentice-Hall, Inc.

Johnson, E. J., \& Russo, J. E. (1984). Product familiarity and learning new information. Journal of consumer research, 542-550. http://dx.doi.org/10.1086/208990

Kamphuis, C., Giskes, K., de Bruijn, G. J., Wendel-Vos, W., Brug, J., \& Van Lenthe, F. J. (2006). Environmental determinants of fruit and vegetable consumption among adults: A systematic review. British Journal of Nutrition, 96(4), 620-635. http://dx.doi.org/10.1079/BJN20061896

Kamphuis, C., van Lenthe, F. J., Giskes, K., Brug, J., \& Mackenbach, J. P. (2007). Perceived environmental determinants of physical activity and fruit and vegetable consumption among high and low socioeconomic groups in the Netherlands. Health \& place, 13(2), 493-503. http://dx.doi.org/10.1016/j.healthplace.2006.05.008

Kuester, S. (2012). MKT 301: Strategic Marketing \& Marketing in Specific Industry Contexts (p. 110). University of Mannheim.

Laurent, G., \& Kapferer, J. N. (1985). Measuring consumer involvement profiles. Journal of Marketing Research (JMR), 22(1). http://dx.doi.org/10.2307/3151549

Marks, L. J., \& Olson, J. C. (1981). Towards a cognitive structure conceptualization of product familiarity. Advances in consumer research, 8(1), 145-150. Retrieved from http://www.acrwebsite.org/search/view-conference-proceedings.aspx?Id=9800

McCarthy, E. J., \& Perreault, W. D. (1984). Basic Marketing. Homewood, IL: Richard D. Irwin. Inc (Warwick: HO $5000 \mathrm{M} 2$ ).

McQuarrie, E. F., \& Munson, J. M. (1987). The Zaichkowsky Personal Involvement Inventory: Modification and Extension. Advances in consumer research, 14(1), 36-40. Retrieved from $\mathrm{http} / / /$ www.acrwebsite.org/search/view-conference-proceedings.aspx?Id=6631

Pallant, J. (2010). SPSS survival manual: A step by step guide to data analysis using SPSS (4th ed., pp. 97-100). England: Open University Press.

Peter, J. P., \& Olson, J. C. (2011). Customers' product knowledge and involvement. Retrieved from $\mathrm{http} / / /$ answers.mheducation.com/marketing/consumer-behavior/customers-product-knowledge-and-involve ment

Punj, G. N., \& Staelin, R. (1983). A model of consumer information search behavior for new automobiles. Journal of Consumer Research, 9(4), 366-380. http://dx.doi.org/10.1086/208931

Sabbe, S., Verbeke, W., \& Van Damme, P. (2008). Familiarity and purchasing intention of Belgian consumers for fresh and processed tropical fruit products. British food journal, 110(8), 805-818. http://dx.doi.org/10.1108/00070700810893331 
Shin, D.-H., \& Shin, Y.-J. (2011). Why do people play social network games? Computers in Human Behavior, 27(2), 852-861. http://dx.doi.org/10.1016/j.chb.2010.11.010

Sirgy, M. J. (1982). Self-concept in consumer behavior: A critical review. Journal of consumer research, 9(3), 287-300. http://dx.doi.org/10.1086/208924

Sujan, M., \& Bettman, J. R. (1989). The effects of brand positioning strategies on consumers' brand and category perceptions: Some insights from schema research. Journal of Marketing Research, 26(4), 454-467. http://dx.doi.org/10.2307/3172765

Tabachnik, B. G., \& Fidell, L. S (2001). Using multivariate statistics (4th ed.). Boston, MA: Allyn \& Bacon.

Tan, C. T., \& Dolich, I. (1981). The Moderating Effects of Cognitive Complexity and Prior Product Familiarity on the Predictive Ability of Selected Multi-Attribute Choice Models for Three Consumer Products. Advances in Consumer Research, 8(1), 140-144. Retrieved from http://ink.library.smu.edu.sg/lkcsb_research/171/

Wardle, J., Haase, A. M., Steptoe, A., Nillapun, M., Jonwutiwes, K., \& Bellisie, F. (2004). Gender differences in food choice: The contribution of health beliefs and dieting. Annals of Behavioral Medicine, 27(2), 107-116. http://dx.doi.org/10.1207/s15324796abm2702_5

Zaichkowsky, J. L. (1985). Familiarity: Product use, involvement or expertise. Advances in consumer research, 12(1), 296-299. Retrieved from http:/www.acrwebsite.org /search/view-conference-proceedings.aspx? Id=6403

\section{Copyrights}

Copyright for this article is retained by the author(s), with first publication rights granted to the journal.

This is an open-access article distributed under the terms and conditions of the Creative Commons Attribution license (http://creativecommons.org/licenses/by/3.0/). 